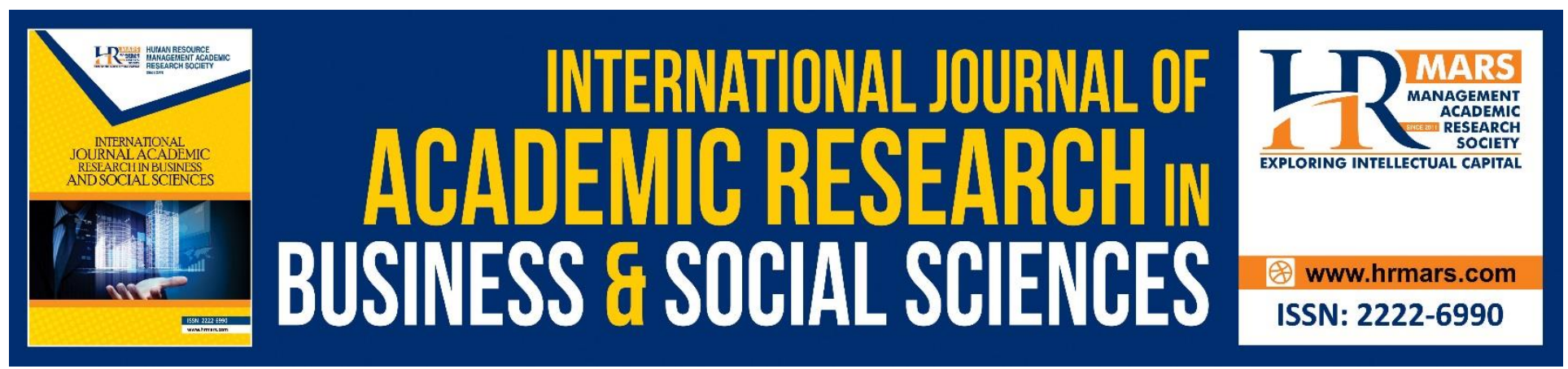

\title{
Social Media Website's Impact on Moral and Social Behavior of the Students of University
}

\author{
Fathi Alshare, Abdelbaset M. Alkhawaldeh and Bilal M. Eneizan
}

To Link this Article: http://dx.doi.org/10.6007/IJARBSS/v9-i3/5646 DOI: $10.6007 /$ IJARBSS/v9-i3/5646

Received: 09 Feb 2019, Revised: 12 March 2019, Accepted: 28 March 2019

Published Online: 13 April 2019

In-Text Citation: (Alshare, Alkhawaldeh, \& Eneizan, 2019)

To Cite this Article: Alshare, F., Alkhawaldeh, A. M., \& Eneizan, B. M. (2019). Social Media Website's Impact on Moral and Social Behavior of the Students of University. International Journal of Academic Research in Business and Social Sciences, 9(3), 169-182.

\section{Copyright: (C) 2019 The Author(s)}

Published by Human Resource Management Academic Research Society (www.hrmars.com)

This article is published under the Creative Commons Attribution (CC BY 4.0) license. Anyone may reproduce, distribute, translate and create derivative works of this article (for both commercial and non-commercial purposes), subject to full attribution to the original publication and authors. The full terms of this license may be seen

at: $\underline{\text { http://creativecommons.org/licences/by/4.0/legalcode }}$

Vol. 9, No. 3, 2019, Pg. 169 - 182

http://hrmars.com/index.php/pages/detail/IJARBSS

JOURNAL HOMEPAGE

Full Terms \& Conditions of access and use can be found at http://hrmars.com/index.php/pages/detail/publication-ethics 


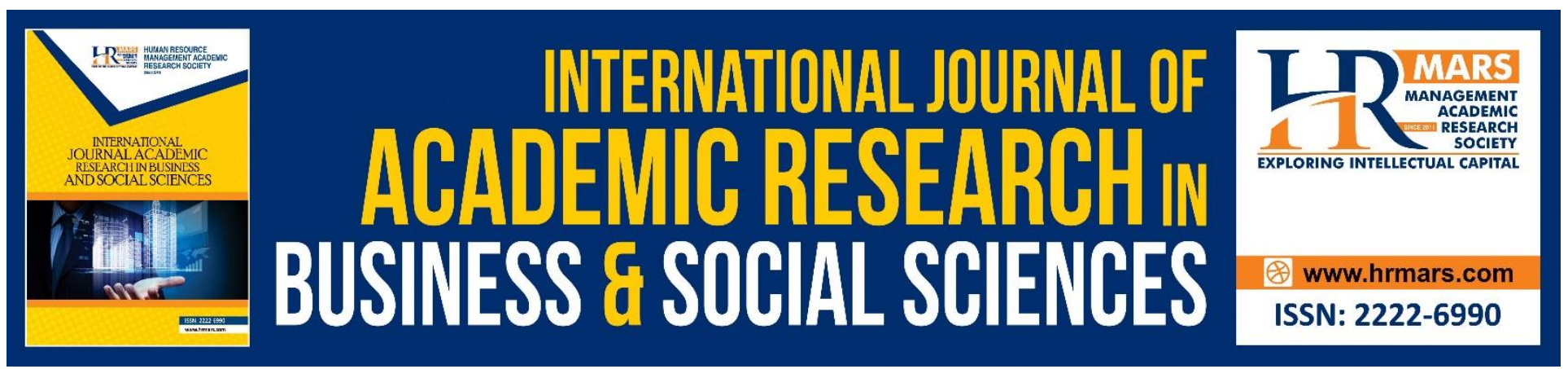

\title{
Social Media Website's Impact on Moral and Social Behavior of the Students of University
}

\author{
Fathi Alshare ${ }^{1}$ Abdelbaset M. Alkhawaldeh ${ }^{2}$ and Bilal M. Eneizan ${ }^{3}$ \\ ${ }^{1}$ Associate Professor, Department of Marketing, Jadara University, Jordan \\ 2,3 Assistant Professor, Department of Marketing, Jadara University, Jordan
}

\begin{abstract}
The study aimed to identify the impact of social media websites on the moral and social behavior of the students of Jordanian universities. A questionnaire was adopted and distributed among 1000 students from Jordanian universities. The Statistical Package for the Social Science version 23.0 was used to analyze the data. The findings of the study indicated that the social media websites (Facebook, Twitter, YouTube, and WhatsApp) have an impact on developing the moral and social attitudes of the students of Jadara University of Jordan, there are differences in the responses of the sample of the study concerning the development of the moral and social attitudes due to gender, age, qualification and knowledge of English language and academic level control variables. The study recommended controlling the social media websites and spreading the awareness among students about the importance of using social media websites and not sitting for long periods because of health risks, reducing their negative effects, wasting of production capacity resulting from webaddiction that may cause wasting their future.
\end{abstract}

Keywords: Social media websites, morals, Facebook, Twitter, YouTube, WhatsApp.

\section{Introduction}

In the past, the social communication of people depended on face to face meetings. With the development of culture and science, human communication capabilities increased with lack of dependence on the direct, face-to-face relationships (Alshare, 2018; Mostafa \& Eneizan, 2018). Regardless of the form of the techniques used in communication, it is important to focus on the role of the communication processes as an indispensable activity in asserting the social existence of man (Ahmed, 2013; Al-Salaymeh \& Alkhawaldeh, 2019; Al-Zawahreh, Mahmoud \& Alkhawaldeh, 2018). However, the conflicting beliefs and ideas crashed resulting in disputes and conflicts with the birth of the human society; they were developed into cultural hostilities based on ideas' confliction. Therefore, the emergence of a science examines that the dynamics of interaction among individuals 
despite their differences, and attempts to establish bases for understanding and communication that may reduce both time and effort (Abed, 2012).

The technological progress, uncountable dimensions, elimination of borders and the close distances made the world a small village for the students that cause exchange in culture and information, particularly in a fast technology, introducing both good and bad things to the consuming community as well as universities that are far from some ethical, social and cultural standards (Eneizan et al,. 2018; Eneizan et al,. 2016a; Eneizan et al,. 2016b). One of these technologies include the social media websites (Facebook, Messenger, Twitter, YouTube, WhatsApp, etc.) which used by the clear majority of young adults (Alshare, 2010; Fuchs, 2017; Gahagan, Vaterlaus, \& Frost, 2016).

A communication revolution brought a great transfer in the world of communication, which contributed to changing the consumption patterns, especially the moral and social patterns among students. The social media websites, especially Facebook, have played a prominent role in the political, economic, social and moral aspects of the life of human societies around the world. Their impact has become evident to all citizens in all walks of life since many students are linked to such social media websites regardless of their pros and cons. Most Arabs, for example, use the Internet to chat with their friends or find new friends compared to other people who use the Internet for other purposes such as learning, electronic shopping or other beneficial purposes (Eneizan et al,. 2016a; Eneizan et al,. 2016b).

Accordingly, it could be said that there are positive and negative aspects for the social media websites, especially on the moral and social aspects of communities, particularly the students who represent the study sample.

\section{Problem Statement}

Social networking websites are one of the big issues (Al-Smadi, 2017; Light \& McGrath, 2010). The problem of the study is highlighted by the ambiguity that reveals the social media websites towards the social and moral responsibility that is associated with the students in general and the Jordanian students in particular. It also underscores the lack of awareness of the risks that might affect the community and resulting from some wrong behaviors despite the positive marketing aspects done by the social media websites. The social media websites may play an important marketing role towards the social and ethical responsibility through the establishment of pages focusing on the social and moral issues of students, working on marketing and developing them.

\section{Objectives of the Study}

The study seeks to achieve the following objectives:

1- To investigate the impact of social media websites (Facebook, Twitter, YouTube, and WhatsApp) on the moral and social behavior of Jordanian students.

2- To differentiate the impact of social media websites among control variables of (income, age, culture, and gender) and the development of the moral and social behavior of the Jordanian students. 


\section{Study Hypotheses}

- There are statistically significant differences between the social media websites (Facebook, Twitter, YouTube, and WhatsApp) and the development of the moral and social aspects of the Jordanian students.

- There are statistically significant differences between the social media websites (Facebook, Twitter, YouTube, and WhatsApp) due to the control variables of (age, income, culture, and gender) and the development of the moral and social aspects of the Jordanian students.

Sub-assumptions of the main hypothesis:

1. There is no statistically significant relationship between the social media websites (Facebook, Twitter, YouTube, and WhatsApp) due to age variable and the development of the moral and social aspect of the Jordanian students.

2. There is no statistically significant relationship between social media websites (Facebook, Twitter, YouTube, and WhatsApp) due to the income variable and the development of the moral and social aspect of the Jordanian students.

3. There is no statistically significant relationship between social media websites (Facebook, Twitter, YouTube, and WhatsApp) due to culture and the development of the moral and social aspects of the Jordanian students.

4. There is no statistically significant relationship between the social media websites (Facebook, Twitter, YouTube, and WhatsApp) due to gender variable and the development of the moral and social aspects of the Jordanian students.

\section{Literature Review}

Lau (2017): "Effects of social media usage and social media multitasking on the academic performance of university students." The study examined whether and how social media usage and social media multitasking predict academic performance among university students in Hong Kong. The study found that using social media for academic purposes was not a significant predictor of academic performance, whereas using social media for nonacademic purposes (video gaming in particular) and social media multitasking significantly negatively predicted academic performance.

Alarabiat and Al-Mohammad (2015): "The Potential for Facebook Application in Undergraduate Learning: A Study of Jordanian Students." The purpose of study was to explore the current and potential use of Facebook for learning purposes by Jordanian university students. Findings indicated that the vast majority of Jordanian students had Facebook accounts and Jordanian students had a positive attitude toward the use of "Facebook groups" as an educational tool.

Raafat (2014): "The impact of using the pre-ethical social networking websites of the Saudi youth: a field study". This study aimed at identifying the impact of social media websites on the ethical values of the young Saudis. It indicated that the networks under study had an impact on the ethical behavior of the Saudi youth and influenced the ethical and moral values. It recommended the need to pay attention to the danger of such networks on the impact of social and ethical values, especially violence and the negative concept of self.

Al-Citi (2013): "The impact of social networking websites on the students of schools and universities: negatives, solutions, and suggestions." The study aimed to identify the impact of social networking websites on school and university students. The results of the study showed that the 
social networking websites caused a qualitative change among students at school and led to a decrease in their educational achievement due to their preoccupation, online games, and internet as well as an increase in the phenomenon of violence and cheating among them. It recommended using tools to punish those who break the moral and social aspect in addition to cheating at the exams.

Ahmed (2013): "The housewife's use of the social networking website (Facebook) and its relation to her different roles." The study aimed to identify the impact of Facebook on the roles done by women according to a group of social and economic variables. The study concluded the presence of a positive and correlational relationship between the family use of the social networking website (Facebook) and its relationship to the different roles.

Awad (2013): "The impact of the social networking websites on the development of social responsibility among youth/ the youth council experience as a model". The study aimed to examine the impact of social networking websites on the development of social responsibility on the youth group. The social responsibility scale was applied before and after the exposure to the social networking websites. The study concluded that there were statistically significant differences from the mean degrees of the members of the experimental group before and after the program in favor of the group after applying for the training program. It also showed that there are no statistically significant differences between the mean degrees of males and females in the experimental group on the level of social responsibility after applying for the program. The study recommended educating the youth on the role played by the social networking websites and their impact on developing their personalities as well as the optimal use of social networking websites.

Hafez (2011): "The university youth communication through social networks: a social phenomenon or a technical necessity". The study concluded that the youth's addiction of spending more time using the social networks led to decreased friendly relations at the level of the family and the community as a whole; it also led to a decline in the personal communication with others, the socalled phenomenon of social alienation.

Vansoon (2010): "The impact of using social networking websites on social relationships". The study was conducted on 1600 users of the social networking websites in the UK. It concluded that more than half of the adults using social networking websites spend more time than with their families or friends in addition to the fact that such websites changed their social lives and behaviors.

\section{Research Methodology}

The study's population consisted of university students. The questionnaire was distributed to (1100) male and female students at Jadara University through a simple, random method of different levels of specialization and study; (1045) questionnaires were retrieved. After reviewing the questionnaires, the researcher excluded 45 questionnaires due to their incomplete data as well as (1000) questionnaires due to the lack of seriousness in filling them; therefore, the total number of the members of the study sample was (1000), male and female. Table (1) shows the distribution of the sample members according to the personal variables. 
INTERNATIONAL JOURNAL OF ACADEMIC RESEARCH IN BUSINESS AND SOCIAL SCIENCES

Vol. 9, No. 3, March, 2019, E-ISSN: 222 2-6990 ¿ 2019 HRMARS

Table (1): Distribution of the sample members according to the personal variables $(n=1000)$

\begin{tabular}{|l|l|l|l|}
\hline Variable & Level & Frequency & Percentage \\
\hline \multirow{4}{*}{ Gender } & Male & 560 & 56 \\
\cline { 2 - 4 } & Female & 440 & 44 \\
\cline { 2 - 4 } & Total & 1000 & 100 \\
\hline \multirow{5}{*}{ Age } & $18-22$ & 600 & 60 \\
\cline { 2 - 4 } & $22-26$ & 360 & 36 \\
\cline { 2 - 4 } & $26-30$ & 40 & 4 \\
\cline { 2 - 4 } & Total & 1000 & 100 \\
\hline \multirow{5}{*}{ Dchool year } & First & 100 & 10 \\
\cline { 2 - 4 } & second & 220 & 22 \\
\cline { 2 - 4 } & Third & 340 & 34 \\
\cline { 2 - 4 } & Fourth & 340 & 34 \\
\cline { 2 - 4 } & Total & 1000 & 100 \\
\hline \multirow{5}{*}{ Knowledge in the English Language } & BA & 959 & 95.9 \\
\cline { 2 - 4 } & MA & 41 & 4.1 \\
\cline { 2 - 4 } & Total & 1000 & 100 \\
\cline { 2 - 4 } & Excellent & 200 & 20 \\
\cline { 2 - 4 } & Wedium & 720 & 72 \\
\cline { 2 - 4 } & Total & 80 & 8 \\
\hline & & & 1000 \\
\hline
\end{tabular}

The percentage of distribution of the sample members according to the variable of male gender was (56\%) while it was (44\%) for the female gender. The highest percentage of the distribution of the sample members according to the variable of knowledge in English was (72\%) for the excellent level, while the lowest percentage was (8\%) for the weak level.

\section{Method and Procedures}

To analyze the data and test the hypotheses of the study, the researcher adopted the Likert fifth scale in answering the questions. Regarding the limitations adopted by this study when commenting on the arithmetic mean of the variables contained in the study model, the researcher determined the degree of approval through three levels (high, medium, low) according to the following equation: Length of the period $=$ (the upper limit of the alternative - the lower limit of the alternative) $/$ the number of levels

$(5-1) / 3=4 / 3=1.33$. Thus, the levels are as follows:

- Low approval level (1- less than 2.33).

- Medium approval level (2.33-less than 3.67).

- High approval level (higher than 3.67-5). 


\section{Tool Validity and Reliability}

To confirm the validity and reliability of the tool, the researcher subjected it to a group of tests, most important of which are:

1. Virtual honesty test: the questionnaire was presented to a number of professors of Jordanian public and private universities of experience and competence; their viewpoints were considered then the corrected correlation coefficient was calculated (0.85).

2. Reliability: In order to test the reliability, the researcher applied the study tool to a sample of 50 male and female students from outside the original study sample. The researcher used Cronbach Alpha coefficient for the internal consistency. The value of Cronbach Alfa was (0.84), which is good for the purposes of circulating the results of the current study; the percent accepted for circulating the results of such studies is $(0.60)$.

\section{Results and Hypotheses Testing}

First hypothesis: There is a statistically significant impact at the level of significance $(\alpha=0.05)$ for the social media websites (Facebook, Twitter, YouTube, and WhatsApp) in developing the moral and social aspect of the students of Jadara University.

The arithmetic means and standard deviations of the answers of the members of the study sample were extracted for the items of the social networking websites in the development of the moral and social aspect, and One Sample T-test was applied to test the first hypothesis of the study, tables (45) illustrate this.

Table (2) the arithmetic means and standard deviations of the answers of the members of the study sample on the items of the field of the social media websites in the development of the moral and social aspect in a descending order

\begin{tabular}{|r|r|l|l|l|l|}
\hline Rank & No & \multicolumn{1}{|c|}{ Item } & $\begin{array}{r}\text { Arithmetic } \\
\text { Mean }\end{array}$ & $\begin{array}{l}\text { Standard } \\
\text { Deviation }\end{array}$ & $\begin{array}{r}\text { Evaluation } \\
\text { degree }\end{array}$ \\
\hline 1 & 1 & $\begin{array}{l}\text { The social media websites contributed to } \\
\text { developing the moral and social aspects. }\end{array}$ & 3.92 & 1.15 & High \\
\hline 2 & 2 & $\begin{array}{l}\text { Ifeel close to my friends and loved ones when } \\
\text { using social media websites. }\end{array}$ & 3.88 & 1.05 & High \\
\hline 3 & 6 & $\begin{array}{l}\text { Your use of social media websites has made } \\
\text { you maintain your old relationship with } \\
\text { friends. }\end{array}$ & 3.68 & 1.19 & Medium \\
\hline 4 & 4 & $\begin{array}{l}\text { You feel that social media websites allowed me } \\
\text { to speak frankly at various places more than } \\
\text { face-to-face communication. }\end{array}$ & 3.62 & 1.15 & Medium \\
\hline 6 & 3 & $\begin{array}{l}\text { The social media websites have allowed me to } \\
\text { benefit from the experiences of others. } \\
\text { and satisfy my desires. }\end{array}$ & 3.62 & 1.28 & Medium \\
\hline 7 & 7 & $\begin{array}{l}\text { You feel that social media websites have } \\
\text { created a gap between you and your family. }\end{array}$ & 3.30 & 1.30 & Medium \\
\hline
\end{tabular}


INTERNATIONAL JOURNAL OF ACADEMIC RESEARCH IN BUSINESS AND SOCIAL SCIENCES

Vol. 9, No. 3, March, 2019, E-ISSN: 222 2-6990 @ 2019 HRMARS

\begin{tabular}{|c|c|c|c|c|c|}
\hline Rank & No & Item & $\begin{array}{r}\text { Arithmetic } \\
\text { Mean }\end{array}$ & $\begin{array}{c}\text { Standard } \\
\text { Deviation }\end{array}$ & $\begin{array}{r}\text { Evaluation } \\
\text { degree }\end{array}$ \\
\hline 8 & 8 & $\begin{array}{l}\text { I did not feel that social media websites } \\
\text { changed my social and moral behavior towards } \\
\text { society. }\end{array}$ & 3.26 & 1.25 & Medium \\
\hline 9 & 9 & $\begin{array}{l}\text { You feel that your social activities in the family } \\
\text { events have decreased since you used the } \\
\text { social media websites. }\end{array}$ & 3.02 & 1.33 & Medium \\
\hline 10 & 12 & I feel regret when using social media websites & 2.86 & 1.42 & Medium \\
\hline 11 & 10 & $\begin{array}{l}\text { I feel an emotional and social emptiness, which } \\
\text { made me escape to using social media } \\
\text { websites. }\end{array}$ & 2.72 & 1.40 & Medium \\
\hline 12 & 11 & $\begin{array}{l}\text { The social media websites have changed my } \\
\text { ethics and my relationship with others } \\
\text { negatively. }\end{array}$ & 2.70 & 1.46 & Medium \\
\hline \multicolumn{3}{|l|}{ Total } & 3.34 & 0.59 & Medium \\
\hline
\end{tabular}

The above table shows that the arithmetic means of the answers of the study sample on the items of the "social media websites in the development of the moral and social aspect" ranged between (2.703.92). Item (1) which states "The social media websites contributed to developing the moral and social aspects," ranked first by an arithmetic mean of (3.92) with a high evaluation degree. While item (11) which states "The social media websites have changed my ethics and my relation with others negatively" came in the last rank with an arithmetic mean of (2.70) and a medium evaluation degree. The arithmetic mean of the field as a whole was (3.34) by a medium evaluation degree.

Table (3): Results of applying (One Sample T-test) on the tool as a whole ( $n=1000)$

\begin{tabular}{|l|l|l|l|l|l|}
\hline Hypothesis & $\begin{array}{r}\text { Arithmetic } \\
\text { Mean }\end{array}$ & $\begin{array}{r}\text { Standard } \\
\text { Deviation }\end{array}$ & T & $\begin{array}{r}\text { Degrees } \\
\text { of } \\
\text { freedom }\end{array}$ & $\begin{array}{r}\text { Statistical } \\
\text { significance }\end{array}$ \\
\hline $\begin{array}{l}\text { There is a statistically } \\
\text { significant impact at the level } \\
\text { of significance } \alpha=0.05) \text { for } \\
\text { the social media websites } \\
\text { (Facebook, Twitter, YouTube, } \\
\text { and WhatsApp) in the } \\
\text { development of the moral } \\
\text { and social aspect of the } \\
\text { Jordanian students. }\end{array}$ & 0.34 & 3.55 & 999 & 0.00 \\
\hline
\end{tabular}

In the previous table, there is a statistically significant impact at the level of $(\alpha=0.05)$ for the social media websites (Facebook, Twitter, YouTube, and WhatsApp) in the development of the moral and the social aspects of the Jordanian students. The value of $(T)$ was (3.55), which is statistically 
significant at the level $(\alpha=0.05)$ and the standard grade of the fifth gradation was (3). Accordingly, the hypothesis is accepted in its fixed form and the alternative formula is rejected.

Second hypothesis: There are statistically significant differences at the level of significance $(\alpha=0.05)$ in the viewpoints of the members of the study sample on the impact of the social media websites (Facebook, Twitter, YouTube and WhatsApp) in the development of the moral and social aspect due to the personal variables of (gender, age, school year, degree and knowledge).

To validate this hypothesis, Independent Samples T-Test was applied on the impact of the social media websites (Facebook, Twitter, YouTube, and WhatsApp) in the development of the moral and social aspect as a whole according to the variable of (gender and degree). ANOVA analysis was also applied on the impact of the social media websites (Facebook, Twitter, YouTube, and WhatsApp) in the development of the moral and social aspect as a whole according to the variables of (age, income, and culture). Tables (6-13) illustrate this.

Table (4): Results of applying the Independent Samples T-Test on the impact of the social networking websites (Facebook, Twitter, YouTube, and WhatsApp) in developing the moral and social aspect as a whole depending on the variable of gender.

\begin{tabular}{|l|l|l|l|c|}
\hline Gender & Arithmetic Mean & Standard Deviation & T & Statistical significance \\
\cline { 1 - 3 } Male & 3.52 & 0.62 & 11.76 & 0.01 \\
\cline { 1 - 3 } Female & 3.11 & 0.42 & & \\
\hline
\end{tabular}

The previous table shows that there are statistically significant differences at the level of significance $(\alpha=0.05)$ in the responses of the sample members on the item of the development of the moral and social aspect due to the variable of gender, in favor of males by an arithmetic mean of (3.52) and for the females (3.11).

Table (5): ANOVA analysis of the impact of the social media websites (Facebook, Twitter, YouTube, and WhatsApp) in the development of the moral and social aspect according to the variable of age.

\begin{tabular}{|l|l|l|l|l|}
\hline Age & Arithmetic Mean & Standard Deviation & F & Statistical significance \\
\hline $18-22$ & 3.39 & 0.60 & & \\
& 3.31 & 0.57 & \multirow{2}{*}{26.68} & 0.00 \\
\hline 26 and above & 2.71 & 0.21 & & \\
\hline Total & 3.34 & 0.59 & & \\
\hline
\end{tabular}

The previous table shows that there are statistically significant differences at the level of $(\alpha=0.05)$ of the responses of the students on the impact of the social media websites (Facebook, Twitter, YouTube and WhatsApp) in the development of the moral and social aspect depending on the different age, where the value of $F$ was (26.68), which is a statistically significant value. To find out the sources of these differences, the Scheffe method of post hoc comparisons was applied as shown in the table (8). 
Table (6): The results of applying the Scheffe method of post hoc comparisons on the impact of the social media websites (Facebook, Twitter, YouTube, and WhatsApp) in the development of the moral and social aspect depending on the variable of age.

\begin{tabular}{|l|l|l|l|l|}
\hline Age & Arithmetic Mean & $\mathbf{1 8 - 2 2}$ & $\mathbf{2 2 - 2 6}$ & 26 and above \\
\hline $18-22$ & 3.39 & & 0.08 & $0.68^{*}$ \\
\hline $22-26$ & 3.31 & & & $0.60^{*}$ \\
\hline 26 and above & 2.71 & & & \\
\hline
\end{tabular}

* Statistically significant at the level of $(\alpha=0.05)$.

The previous table shows that the sources of the differences were between the age groups of (18-22 and 26 and above) for the benefit of the age group (18-22 years) by an arithmetic mean of (3.39); however, the arithmetic mean for the age group (26 years and above) was 3.31. There were differences between the age groups of (22-26 years, 26 years and above) for the age group (22-26) by an arithmetic mean of 3.31 .

Table (7): ANOVA on the impact of social media websites (Facebook, Twitter, YouTube, and WhatsApp) in developing the moral and social aspect according to the variable of the academic level.

\begin{tabular}{|l|l|l|l|l|}
\hline Academic Level & Arithmetic Mean & Standard Deviation & F & $\begin{array}{l}\text { Statistical } \\
\text { significance }\end{array}$ \\
\hline first year & 3.57 & 0.52 & & \\
\cline { 1 - 2 } second year & 3.52 & 0.61 & \multirow{2}{*}{19.73} & 0.00 \\
\hline third year & 3.20 & 0.46 & & \\
\hline fourth year & 3.29 & 0.67 & & \\
\hline Total & 3.34 & 0.59 & \\
\hline
\end{tabular}

The previous table shows that there are statistically significant differences at the level of $(\alpha=0.05)$ for the responses of the students on the impact of the social media websites in the development of the moral and social aspect according to the different academic level where the (F) value was (19.73), which is statistically significant. To find out the sources of these differences, the Scheffe method of post comparisons was applied. Table (10) illustrates this.

Table (8): The results of applying the Scheffe method of post hoc comparisons on the development of the moral and social aspect according to the variable of the school year

\begin{tabular}{|l|l|l|l|l|l|}
\hline School Year & Arithmetic Mean & first year & second year & third year & fourth year \\
\hline first year & 3.57 & & 0.05 & $0.37^{*}$ & 0.28 \\
\hline second year & 3.52 & & & $0.35^{*}$ & 0.23 \\
\hline third year & 3.20 & & & & 0.09 \\
\hline fourth year & 3.29 & & & & \\
\hline
\end{tabular}

* Statistically significant at the level of $(\alpha=0.05)$.

The previous table shows that the sources of the differences were between the levels of the school year (first year, third year) for the benefit of the school year (first year) by an arithmetic mean of 
INTERNATIONAL JOURNAL OF ACADEMIC RESEARCH IN BUSINESS AND SOCIAL SCIENCES

Vol. 9, No. 3, March, 2019, E-ISSN: 222 2-6990 @ 2019 HRMARS

(3.57). However, the arithmetic means of the level of the school year (third year) had an arithmetic mean of (3.20), while the source of the differences between the levels of the school year (second year, third year) was for the benefit of the (second year) by an arithmetic mean of (3.52).

Table (9): Results of applying the Independent Samples T-Test on the field of the development of the moral and social aspect as a whole according to the variable of the academic qualification.

\begin{tabular}{|l|l|l|l|c|}
\hline Degree & Arithmetic Mean & Standard Deviation & $\mathbf{T}$ & Statistical significance \\
\hline BA & 3.32 & 0.59 & \multirow{2}{*}{3.41} & 0.00 \\
\hline MA & 3.63 & 0.55 & & \\
\hline
\end{tabular}

The previous table shows that there are statistically significant differences at the level of $(\alpha=0.05)$ in the responses of the sample of the study on the item of the impact of the social media websites (Facebook, Twitter, YouTube, and WhatsApp) in the development of the moral and social aspect due to the variable of academic qualification. The $(T)$ value was (3.41), which is statistically significant for the benefit of the (MA) degree by an arithmetic mean of (3.63), while the arithmetic means of the (BA) degree was (3.32).

Table (10): ANOVA analysis on the item of the study tool according to the knowledge of English language variable.

\begin{tabular}{|l|l|l|l|l|}
\hline Knowledge & Arithmetic Mean & Standard Deviation & F & Statistical significance \\
\hline Excellent & 3.77 & 0.58 & & \multirow{2}{*}{80.43} \\
\hline Medium & 3.24 & 0.55 & & \\
\hline Weak & 3.15 & 0.45 & & \\
\hline
\end{tabular}

The previous table shows that there are statistically significant differences at the level of $(\alpha=0.05)$ for the responses of the students on the item of the impact of the social media websites (Facebook, Twitter, YouTube, and WhatsApp) in the development of the moral and social aspect according to the difference in knowledge of English language. The (F) value was (80.43), which is statistically significant. To find out the sources of these differences, the Scheffe method of post hoc comparisons was applied. Table (13) shows that

Table (11): Results of applying the Scheffe method of post hoc comparisons on the development of the moral and social aspect according to the variable of knowledge of the English language.

\begin{tabular}{|l|l|l|l|l|}
\hline knowledge & $\begin{array}{l}\text { Arithmetic } \\
\text { Mean }\end{array}$ & Excellent & Medium & Weak \\
\hline Excellent & 3.77 & & $0.53^{*}$ & $0.62^{*}$ \\
\hline Medium & 3.24 & & & 0.09 \\
\hline Weak & 3.15 & & & \\
\hline
\end{tabular}

* Statistically significant at the level $(\alpha=0.05)$.

The previous table shows that the differences among the knowledge levels (excellent, weak) were for the benefit of the (excellent) level by an arithmetic mean of (3.77). While the arithmetic means of (weak) level had the arithmetic mean of (3.15). The results also showed that there are differences 
among the levels of knowledge (excellent, medium) for the benefit of the (excellent) level where the arithmetic mean of (medium) was (3.24).

\section{Results}

After conducting the statistical analysis of the responses of the sample members regarding the study tool, the following results were obtained: There is a statistically significant impact at the level of significance $(\alpha=0.05)$ for the social media websites (Facebook, Twitter, YouTube, and WhatsApp) in the development of the moral and social aspect of the students of Jadara University. There are statistically significant differences at the level of significance $(\alpha=0.05)$ in the responses of the study sample on the development of the moral and social aspect due to a variable of gender in favor of males. There are statistically significant differences at the level of ( $\alpha=0.05)$ for the responses of the students on the impact of the social media websites (Facebook, Twitter, YouTube and WhatsApp) in the development of the moral and social aspect according to age variable for the benefit of the age group (18-22 years). There are statistically significant differences at the level of $(\alpha=0.05)$ for the responses of the students on the impact of the social media websites in developing the moral and social aspect according to the school year variable for the benefit of the school year (first year). There are statistically significant differences at the level of significance $(\alpha=0.05)$ in the responses of the members of the study sample on the field of the impact of the social media websites (Facebook, Twitter, YouTube and WhatsApp) in developing the moral and social aspect due to the variable of academic qualification for the benefit of (MA) degree. There are statistically significant differences at the level of $(\alpha=0.05)$ for the responses of the students on the field of the impact of the social media websites (Facebook, Twitter, YouTube and WhatsApp) in the development of the moral and social aspect according to the variable of knowledge of English language for the benefit of (excellent) level.

\section{Recommendations}

Considering the results, the researcher recommended the followings: Establishing the controls of using social media websites that are suitable with the values of our societies, customs, cultures, and traditions. Also, spreading awareness among the students of both the public and private universities on the importance of using social media websites properly. Moreover, controlling the movements of students on social media websites and using controls to reduce the non-ethical uses in the educational aspect (cheating). In addition, paying attention to spreading scientific and targeted websites among university students to reduce the negative effects of social media websites. Furthermore, educating the university students on using social media websites so that they would not suffer from (addiction to the social media websites) leading to the loss of their future. Finely, spending less time using social media websites due to their health risks and a waste of production capacity because of the addiction it may cause.

\section{References}

Abed, Z. (2012). The role of the social networking websites in directing the Palestinian public opinion towards the social and political change: An analytical descriptive study. Al- Najah University Journal for Research, Humanities, 26 (6) 1387-1428. 
INTERNATIONAL JOURNAL OF ACADEMIC RESEARCH IN BUSINESS AND SOCIAL SCIENCES

Vol. 9, No. 3, March, 2019, E-ISSN: 222 2-6990 @ 2019 HRMARS

Ahmed, S. A. (2013). The housewife's use of the social networking website (Facebook) and its relation to achieving her different roles. Alex.J.Agic.Re,Vol.S \& No3,PP279-97.

Alarabiat, A., \& Al-Mohammad, S. (2015). The Potential for Facebook Application in Undergraduate Learning: A Study of Jordanian Students. Interdisciplinary Journal of Information, Knowledge \& Management, 10.

Alshare, F. (2010). The effect of advertising on consumer behaviour for cans food industries. European journal of social Sciences, 16(3), 340-349.

Alshare, F. (2018). The Role of the Integrated Marketing Communications in highlighting the competitive advantage in the Jordanian Telecommunication Companies (Orange Company: Study Model). International Journal of Academic Research in Business and Social Sciences, 8(4), 573-593.

Al-Citi, A. (2013). The impact of the social networking websites on the students of schools and universities: negatives...solutions...suggestions. Published research (Al-Muallim Kuwaiti Journal).

Al-Mu'ani, L., Saydam, S., and Çaliciolu, C. (2014). Facebook as a marketing communications toolFacebook official pages content analysis for Jordanian telecommunications companies in the mobile operators sector. International journal of business and social science, 5(4).

Al-Salaymeh, M, \& Alkhawaldeh, A. M. (2019). The Impact of Traditional Products and Advertising on Tourists Attraction: A Field Study at Ajloun Governorate. Academic Research International, 10(1), 147- 154.

Al-Smadi, H. S. A. I. (2017). The Role of Social Networking Sites in Creating Moral Crisis and the Role of the University in Confronting It from the View Point of Qassim University Faculty Members. International Education Studies, 10(5), 36-47.

Al-Zawahreh, A., Mahmoud, A. R., \& Alkhawaldeh, A. M. (2018). The Impact of Corporate Social Responsibility on the Performance of Pharmaceutical Companies in Jordan. International Journal of Business and Social Science, 9(12).

Awad, H. (2013). The impact of the social networking websites on the development of the social responsibility among youth. Youth Council experience as a model, a research published on the Internet, Al-Quds Open University.

Eneizan, B. M., Wahab, K. A., \& Wahab, K. A. (2016b). Determining the Factors Influencing Use of Mobile Marketing by Industrial Firms: An Empirical Investigation of Jordanian Industrial Firms. Indian Journal of Computer Science, 1(1), 25-36.

Eneizan, B. M., Zainon, M. S., \& Obaid, T. F. (2016a). Quick response (QR) code and green product purchases: evidence from Jordanian consumers. Singaporean Journal of business economics, and management studies, 5, 4 .

Eneizan, B., Mostafa, A. A., \& Alabboodi, A. S. (2018). Effect of technical support and trust on the adoption of electronic human resource management: Evidence from developing countries. IJAR, 4(7), 31-40.

Evans, D. (2010). Social media marketing: An hour a day. John Wiley \& Sons.

Fadel Allah, W. (2010). The Impact of Facebook on Communities. Khartoom, Shams Al-Nahda Blog.

Fuchs, C. (2017). Social media: A critical introduction. Sage. 
Gahagan, K., Vaterlaus, J. M., \& Frost, L. R. (2016). College student cyberbullying on social networking sites: Conceptualization, prevalence, and perceived bystander responsibility. Computers in human behavior, 55, 1097-1105.

Hafez, A. (2011). The origin of the university youth through social networks: social phenomenon or technical necessity. Published research (Ajman University, United Arab Emirates).

Lau, W. W. (2017). Effects of social media usage and social media multitasking on the academic performance of university students. Computers in human behavior, 68, 286-291.

Li, c. (2010). Open Technology. How Social Technology can transform the way you land Jose-bass. San from ciscco, U.S.A. available on line cat http://books.google.comeg./books.

Light, B., \& McGrath, K. (2010). Ethics and social networking sites: a disclosive analysis of Facebook. Information Technology \& People, 23(4), 290-311.

Moshri, M. (2012). Digital social networks, look at jobs. The Future of the Arab Magazine, Issue 395.

Mostafa, A. A., \& Eneizan, B. (2018). Factors Affecting Acceptance of Mobile Banking in Developing Countries. International Journal of Academic Research in Business and Social Sciences, 8(1), 340351.

Raafat, D. (2014). The impact of using the social and ethical social networking websites of the Saudi youth, a field study. Published research (King Abdulaziz University, Saudi Arabia).

Vansoon, M. (2010). Facebook and the invasion of technological communities. New York. 